\title{
Vitamin D and Its Metabolites Deficiency in Acute Coronary Syndrome Patients Undergoing Coronary Angiography: A Case-Control Study
}

\author{
Hussein $M$ Ismail $^{1,2}$ \\ Abeer S Algrafi $^{2}$ \\ Osama Amoudi ${ }^{3}$ \\ Sameh Ahmed ${ }^{4}$ \\ Sultan S Al-Thagfan (1D ${ }^{5}$ \\ Hassan Shora $\mathbb{D D}^{6}$ \\ Mohammed Aljohani ${ }^{7}$ \\ Mohammed Almutairi ${ }^{7}$ \\ Fahad Alharbi ${ }^{7}$ \\ Abdullah Alhejaili ${ }^{7}$ \\ Majed Alamri ${ }^{7}$ \\ Abdullah Muhawish ${ }^{7}$ \\ Ayat Abdallah $\mathbb{1}^{8,9}$
}

'Department of cardiology, College of Medicine, Suez Canal University, Ismailia, Egypt; ${ }^{2}$ Department of medicine, College of Medicine, Taibah University, Al-Madinah AlMunawara, Saudi Arabia; ${ }^{3}$ Madinah Cardiac Center, Adult cardiology, Al-Madinah AlMunawara, Saudi Arabia; ${ }^{4}$ Department of Pharmacognosy and Pharmaceutical Chemistry, College of Pharmacy, Taibah University, Al-Madinah Al-Munawara, Saudi Arabia; ${ }^{5}$ Department of Clinical and Hospital Pharmacy, College of Pharmacy, Taibah University, Al-Madinah Al-

Munawara, Saudi Arabia; ${ }^{6}$ Department of molecular biology/biochemistry, Port Said University, Port Said, Egypt; ${ }^{7}$ Medical intern, Taibah University, Al-Madinah Al-

Munawara, Saudi Arabia; ${ }^{8}$ Epidemiology and Preventive Medicine Department, National Liver Institute, Shebin El-Kom, Egypt;

${ }^{9}$ Department of Family and Community Medicine, Taibah University, Al-Madinah AlMunawara, Saudi Arabia

Correspondence: Hussein M Ismail Department of Cardiology, College of Medicine, Suez Canal University, Ismailia, Egypt

Email husseinismail@med.suez.edu.eg; drhussein72@gmail.com
Background: Vitamin D deficiency is considered an emerging health problem that affects at least one billion patients worldwide. Calcitriol $1,25(\mathrm{OH})_{2} \mathrm{D}_{3}$ has several systemic effects, including anti-inflammatory, anti-thrombotic and anti-atherosclerotic impacts that explain its cardioprotective effects. The precise association between vitamin D and its metabolites and the value of supplements in acute coronary syndrome (ACS) is still controversial. This study aims to search the association between vitamin $\mathrm{D}_{2}, \mathrm{D}_{3}$, and metabolites and ACS in patients undergoing coronary angiography.

Materials and Methods: This was a case-control study on 73 consecutive adult patients with ACS undergoing coronary angiography compared to 50 controls without coronary artery disease and matched for age and sex from June 2019 till July 2019. Echocardiography and coronary angiography were done for all cases. Plasma vitamin D and its metabolites were measured at admission for all participants along with chemistry profiles.

Results: Vitamin D and its metabolites were statistically significantly lower in ACS patients than the controls. Multivariate regression analysis revealed that low levels of 25hydroxyvitamin $\mathrm{D}(25(\mathrm{OH}) \mathrm{D})$ and 1,25-dihydroxyvitamin $\mathrm{D}\left(1,25(\mathrm{OH})_{2} \mathrm{D}\right)$ significantly predicted ACS occurrence; the other significant predictors were high systolic blood pressure (BP), high total cholesterol, and low high-density lipoprotein-cholesterol. Interestingly, vitamin $D_{2}$ and $D_{3}$ did not significantly predict ACS $(p>0.05)$. We did not find a statistically significant association between the number of affected coronary vessels and vitamin D metabolites. Moreover, there was no statistically significant correlation between vitamin D and its metabolites and left ventricular ejection fraction measured by echocardiography.

Conclusion: There was a strong association between vitamin $\mathrm{D}$ and all its metabolites with ACS. Significantly, low $25(\mathrm{OH}) \mathrm{D}$ and $1,25(\mathrm{OH})_{2} \mathrm{D}$ predicted $\mathrm{ACS}$, but vitamin $\mathrm{D}_{2}$ and $\mathrm{D}_{3}$ did not. Large randomized controlled trials are needed to verify the beneficial values of vitamin D supplementation in ACS patients.

Keywords: vitamin $\mathrm{D}_{3}$, vitamin $\mathrm{D}_{2}, 25$-hydroxyvitamin $\mathrm{D}, 1,25$-dihydroxyvitamin $\mathrm{D} 3$, acute coronary syndrome, coronary artery disease

\section{Introduction}

Coronary artery disease (CAD) is considered the leading cause of morbidity and mortality worldwide. ${ }^{1}$ New emerging risk factors have been proposed to be significant predictors of atherosclerosis and subsequent complications. Among them, vitamin D deficiency may be involved in the pathogenesis of acute coronary syndrome (ACS). ${ }^{2}$ 
The prevalence of vitamin D deficiency has increased among all populations and ethnicities in the last few years. ${ }^{3}$ It was identified as a pandemic affecting approximately one-third of the Americans, ${ }^{4} 60 \%$ of the Canadians, ${ }^{5}$ and $40 \%$ of the Europeans. ${ }^{6}$ Additionally, in Saudi Arabia, low 25-hydroxy vitamin D $(25(\mathrm{OH}) \mathrm{D})$ was found in $36.8 \%$ to $62.65 \%$ of females and $17.7 \%$ to $40.6 \%$ of males. ${ }^{7,8}$

In addition to the effects of vitamin $\mathrm{D}$ on calcium homeostasis, ${ }^{9}$ it has beneficial anti-inflammatory and antiatherosclerotic effects. ${ }^{10}$ Moreover, hypovitaminosis D has been associated with atherosclerotic cardiovascular disease (CVD) ${ }^{2}$ higher post-ACS complications, ${ }^{11}$ and metabolic diseases, eg, metabolic syndrome and insulin resistance. ${ }^{12}$

While the exact mechanism of increased cardiovascular risk in patients with vitamin D deficiency has not yet been established, multiple hypotheses have been postulated. Vitamin D receptors (VDRs) have been distributed widely throughout the cardiovascular system. ${ }^{13}$ Vitamin $\mathrm{D}$ reduces cardiac ischemia-reperfusion injury and reactive oxygen species ${ }^{14}$ and shows favourable effects on inflammation and thrombosis. ${ }^{15}$ Additionally, low 25(OH)D levels promote atherosclerosis, chronic inflammation, endothelial dysfunction and arterial calcification. ${ }^{16}$ Moreover, vitamin D insufficiency may activate the reninangiotensin system ${ }^{17}$ and increase insulin resistance, endothelial dysfunction, inflammation, platelet function, and blood pressure (BP). ${ }^{18}$ Furthermore, an experimental trial revealed that vitamin $\mathrm{D}$ supplementation suppressed vascular inflammation by inhibiting the Nuclear Factor- $\mathrm{\kappa B}$ (NF- $\mathrm{kB}$ ) pathways and decreasing the process of atherosclerosis and hence subsequent CAD. ${ }^{19}$ Additionally, a study demonstrated an inverse association between matrix metalloproteinase 9 and vitamin D in 139 acute myocardial infarction (AMI) patients. ${ }^{20}$

The two forms of vitamin $\mathrm{D}$ are vitamin $\mathrm{D}_{2}\left(\mathrm{D}_{2}\right)$, which is present in plant foods, and vitamin $\mathrm{D}_{3}\left(\mathrm{D}_{3}\right)$, which is formed in the skin upon exposure to sunlight and from animal food. ${ }^{21} \mathrm{D}_{3}$ is three times more effective than $\mathrm{D}_{2}$ in humans. ${ }^{22}$ Both $\mathrm{D}_{2}$ and $\mathrm{D}_{3}$ undergo hepatic hydroxylation at position 25 to generate $25(\mathrm{OH}) \mathrm{D}$, ie, calcidiol. ${ }^{23}$ Further, one $\alpha$-hydroxylation is taken place to produce 1,25-dihydroxyvitamin $\mathrm{D}\left(1,25(\mathrm{OH})_{2} \mathrm{D}\right)$, ie, calcitriol, which is the active form of vitamin $\mathrm{D}$, but it circulates in lower concentrations when compared to 25 (OH)D. ${ }^{24}$

Although several studies were done on the $25(\mathrm{OH}) \mathrm{D}$, there is no single study on the association of different forms of vitamin $\mathrm{D}$ and their metabolites and the acute coronary syndrome on our population. Therefore, it would help to study the potential association between vitamin D forms with their metabolites and ACS in our population.

\section{Methodology \\ Study Population}

The present study is a case-control study that included 73 consecutive adult patients with ACS admitted to the coronary care unit at the Madinah Cardiac Centre, a tertiary care hospital, Al-Madinah Al-Munawara, that is considered one of the referral centres for the western region of Saudi Arabia, during the period from June 2019 till July 2019. The controls were 50 age- and gendermatched subjects free from previous CVD recruited from the attendants or relatives of noncardiac patients. We included adult patients (age $>18$ years old) with ACS. We excluded patients with chronic coronary syndrome, pregnancy, malignancy, thyroid disease, advanced chronic kidney disease (stage 4 or 5), and liver disease.

\section{Collection of Data Clinical Data}

We interviewed the patients and obtained a full history and complete examination. Specifically, the history included personal demographic data and the traditional CVD risk factors. Furthermore, a complete cardiac examination, electrocardiogram (ECG), echocardiography, and diagnostic coronary angiography were done on all patients.

\section{Criteria of Diagnosis of Risk Factors}

Hypertension was considered if the patient was previously diagnosed or on active anti-hypertensive treatment. ${ }^{25}$ The patient was considered diabetic if glycated haemoglobin ( $\mathrm{HbAlc}$ ) is $6.5 \%$ or more, previously diagnosed, or on antidiabetic treatment. ${ }^{26}$ Smoking was considered if patients smoked at least 100 cigarettes or currently smoking. While Ex-smokers were patients who smoked 100 cigarettes or more, but they are not currently smoking, and they have not smoked for two years. Ex-smokers and never-smokers were considered non-smokers. ${ }^{27}$ Serum cholesterol and its lipoproteins are directly linked to the development of CVD. General population studies suggest that the optimal levels of total cholesterol and LDL-C is $150 \mathrm{mg} / \mathrm{dL}(3.8 \mathrm{mmol} / \mathrm{L})$, and $100 \mathrm{mg} / \mathrm{dL}(2.6 \mathrm{mmol} / \mathrm{L})$, respectively. ${ }^{28}$ In cases with a very high risk of CVD, ie, secondary prevention, the target is a reduction of LDL-C 
$\geq 50 \%$ from baseline and an LDL-C goal of $<1.4 \mathrm{mmol} / \mathrm{L}$ $(<55 \mathrm{mg} / \mathrm{dL}){ }^{29}$

HDL-C is associated with the risk of $\mathrm{CVD}^{30}$ even though no specific goals have been set for HDL-C in clinical trials. ${ }^{29}$

\section{Diagnosis of ACS}

The acute myocardial infarction requires at least two of the following: symptoms suggestive of ischemia, diagnostic ECG, and elevated cardiac biomarkers. ${ }^{31}$ ECG suggestive of ACS includes presumably new pathologic Q waves or a new left bundle branch block. Moreover, ST-elevation is $\geq 0.1 \mathrm{mV}$ in 2 or more contiguous limb leads and/or $\geq 0.2$ $\mathrm{mV}$ ST elevation in chest leads. ${ }^{32}$ Unstable angina was diagnosed in patients presenting with symptoms suggestive of ischemia without cardiac biomarker elevation, and ECG might indicate ischemia. ${ }^{33}$

\section{Laboratory Data}

Blood samples were collected from the study subjects under aseptic measures by venipuncture within $24 \mathrm{~h}$ of admission. The samples were immediately centrifuged onsite at $2000 \times \mathrm{g}$ for 10 minutes at $4{ }^{\circ} \mathrm{C}$ and then stored at $-70^{\circ} \mathrm{C}$ until the analysis. Serum samples were thawed at room temperature just before analysis. Serum samples were analyzed at the College of pharmacy-Taibah University laboratories. Serum levels of vitamin D, including $\mathrm{D}_{2}, \mathrm{D}_{3}, 25(\mathrm{OH}) \mathrm{D}$, and $1,25(\mathrm{OH})_{2} \mathrm{D}$, were measured by the ultra-performance liquid chromatography (UPLC) system with a tandem mass detector system, ${ }^{34}$ which was made up of Waters Quattro Premier XE tandem mass spectrometer (Waters Corporation, USA).

Regarding the diagnosis and categorization of serum levels of 25(OH)D deficiency that was based on the United States Endocrine Society guideline, 25(OH)D deficiency was serum level $\leq 20 \mathrm{ng} / \mathrm{mL}$, and $25(\mathrm{OH}) \mathrm{D}$ insufficiency with serum level between 20 and $29.99 \mathrm{ng} / \mathrm{mL}$, while the normal values were $\geq 30 \mathrm{ng} / \mathrm{mL}{ }^{35}$

\section{Ethical Considerations}

This work was done and accepted by the research ethics committee of the faculty of Medicine, Taibah University, Al-Madinah Al-Munawara, Saudi Arabia. All patients who were enrolled in the study agreed on written informed consent. Patients were told that their details would be confidential. The current study was conducted in accordance with the World Medical Association Declaration of Helsinki.

\section{Statistical Analysis}

SPSS 21.0 software was used for data analysis (SPSS Inc. Chicago, USA). All quantitative data were presented by the mean and standard deviation (SD), and they were compared by Student's $t$-test when data were normally distributed, while the Mann-Whitney test has been used when data were not normally distributed. Additionally, all qualitative data were expressed as frequency and per cent, and they were compared by Chi-square test. Pearson's correlation was used to determine the correlation between two quantitative variables with normally distributed data. Meanwhile, Spearman correlation was used to test the correlation between two quantitative variables having non-normally distributed data. Moreover, multiple logistic regression models (the enter mode) have been used to give an adjusted odds ratio and $95 \%$ confidence interval of the effect of different risk factors for ACS. A statistical significance was considered when the $p$-value was below 0.05 .

\section{Results}

The current study included 73 cases with ACS compared to 50 volunteers without a history of ACS as a control group. Overall, the participants' age ranged from 30 to 83 years old, with an overall mean \pm SD of $56.7 \pm 11.5$. The baseline characteristics of our study population were reported in Table 1. In this study, statistically significant differences have been found between cases and controls regarding the medical history of diabetes and hypertension $(\mathrm{p}<0.001)$ (Table 1).

In Table 2, there were statistically significant differences between the ACS cases and the controls regarding the systolic blood pressure $(\mathrm{p}=0.002)$. In addition, blood glucose was significantly higher in the ACS than in the controls. Notably, lipid profile results were also significantly different between the two groups $(p<0.001)$. Haematological parameters such as haemoglobin, white blood cell count, and platelet count showed a significant difference between the ACS and the control groups $(\mathrm{p}<0.001)$

To assess the possible association between vitamin $\mathrm{D}$ and the development of ACS, we measured vitamin $\mathrm{D}_{2}, \mathrm{D}_{3}$ and the metabolites and found that the mean $\pm \mathrm{SD}$ of all measured vitamin D forms and the metabolites were significantly lower in the ACS group than in the control group with a p-value $<0.001$ (Table 3 ). In addition, the 
Table I General Characteristics of Study Participants

\begin{tabular}{|c|c|c|c|c|c|}
\hline \multirow[t]{3}{*}{ Variables } & \multicolumn{4}{|c|}{ Participants $(n=\mid 23)$} & \multirow[t]{3}{*}{ p-value ${ }^{a}$} \\
\hline & \multicolumn{2}{|c|}{$\begin{array}{c}\text { ACS } \\
\text { Cases* } \\
(n=73)\end{array}$} & \multicolumn{2}{|c|}{$\begin{array}{l}\text { Control } \\
(n=50)\end{array}$} & \\
\hline & No & $\%$ & No & $\%$ & \\
\hline \multicolumn{6}{|l|}{ Age: } \\
\hline$<45$ & 6 & 8.2 & 9 & 18.0 & 0.103 \\
\hline$\geq 45$ & 67 & 91.8 & 41 & 82.0 & \\
\hline \multicolumn{6}{|l|}{ Gender: } \\
\hline Male & 57 & 78.1 & 38 & 76.0 & 0.78 \\
\hline Female & 16 & 21.9 & 12 & 24.0 & \\
\hline \multicolumn{6}{|l|}{ History of Diabetes: } \\
\hline No & 27 & 37.0 & 42 & 84.0 & $<0.001 *$ \\
\hline Yes & 46 & 63.0 & 8 & 16.0 & \\
\hline \multicolumn{6}{|l|}{ History of hypertension: } \\
\hline No & 31 & 42.5 & 41 & 82.0 & $<0.001 *$ \\
\hline Yes & 42 & 57.5 & 9 & 18.0 & \\
\hline \multicolumn{6}{|l|}{ Smoking: } \\
\hline No & 47 & 64.4 & 37 & 74.0 & 0.26 \\
\hline Yes & 26 & 35.6 & 13 & 26.0 & \\
\hline \multicolumn{6}{|l|}{ BMI: } \\
\hline Underweight or normal & 26 & 35.6 & 16 & 32.0 & 0.67 \\
\hline Overweight or obese & 47 & 64.4 & 34 & 68.0 & \\
\hline
\end{tabular}

Notes: ${ }^{a}$ Chi square test. *P-value $<0.05$ is considered statistically significant. Abbreviations: ACS, acute coronary syndrome; BMI, body mass index; no, number.

study showed that $25(\mathrm{OH}) \mathrm{D}$ was either deficient or insufficient in all ACS cases (Figure 1).

In the current study, all variables significantly $(\mathrm{p}<0.05)$ associated with ACS in univariate analysis were included in multivariate regression analysis models in addition to age and gender. High systolic blood pressure and high total cholesterol level were independently associated with ACS among participants $(\mathrm{OR}=1.128,95 \% \mathrm{CI}=1.007-1.264)$ and ( $\mathrm{OR}=8.286,95 \% \mathrm{CI}=1.073-63.972)$, respectively. While the lower levels of high-density lipoprotein cholesterol (HDL-C), 25(OH)D, and $1,25(\mathrm{OH})_{2} \mathrm{D}$ were independently associated with ACS among participants $(\mathrm{OR}=0.001,95 \%$ $\mathrm{CI}=<0.001-0.040 ; \quad \mathrm{OR}=0.218, \quad 95 \% \quad \mathrm{CI}=0.065-0.732$; $\mathrm{OR}=0.545,95 \% \mathrm{CI}=0.311-0.956$ ), respectively (Table 4).

As shown in Figure 2, more than half of the ACS cases $(65.8 \%)$ presented with single-vessel CAD. While the frequencies of different affected coronary arteries; left main (LM), left anterior descending (LAD), left circumflex (LCX), and right coronary artery (RCA), were $11.0 \%, 54.8 \%, 34.2 \%$, and $47.9 \%$, respectively among the studied ACS cases. Moreover, the mean \pm SD of the left ventricular ejection fraction was $36.59 \pm 12.46$ in the ACS group. Interestingly, no significant correlations ( $p>0.05$ ) have been found between all the vitamin forms and metabolites and the number of affected vessels (it was ranging from 1 to 3 vessels) and the left ventricular ejection fraction among the studied group of ACS cases (Table 5). Meanwhile, a statistically significant correlation has been found between 25-hydroxyvitamin $\mathrm{D}$ and 1,25-dihydroxyvitamin $\mathrm{D}(\mathrm{p}<0.001, \mathrm{r}=0.88)$ among the same group of patients (Figure 3 ).

\section{Discussion}

Deficiency of vitamin $\mathrm{D}$ is a worldwide health problem with a high prevalence among the general population. ${ }^{36}$ Most

Table 2 Clinical Parameters, Blood Glucose, Lipid Profile, and Hematological Tests Among Participants

\begin{tabular}{|c|c|c|c|}
\hline \multirow[t]{2}{*}{ Parameters } & \multicolumn{2}{|c|}{ Participants $(n=\mid 23)$} & \multirow[t]{2}{*}{ P-value } \\
\hline & ACS Cases $(n=73)$ Mean \pm SD & Controls $(n=50)$ Mean \pm SD & \\
\hline Systolic BP (mmHg) & $129.60 \pm 21.72$ & $118.48 \pm 13.29$ & $0.002 * *$ \\
\hline Diastolic BP (mmHg) & $75.42 \pm 10.64$ & $77.54 \pm 10.29$ & $0.275 * *$ \\
\hline Glucose Level (mg/dL) & $168.86 \pm 63.39$ & $125.75 \pm 25.58$ & $<0.001 * *$ \\
\hline TC (mmol/L) & $4.48 \pm 1.41$ & $3.05 \pm 0.44$ & $<0.001 * *$ \\
\hline LDL-C (mmol/L) & $2.90 \pm 1.24$ & $1.92 \pm 0.69$ & $<0.00 I^{*}$ \\
\hline HDL-C (mmol/L) & $1.00 \pm 0.25$ & $1.18 \pm 0.12$ & $<0.001 * *$ \\
\hline Triglycerides (mmol/L) & $1.24 \pm 0.77$ & $1.21 \pm 0.81$ & $0.36 I^{*}$ \\
\hline $\mathrm{Hb}(\mathrm{g} / \mathrm{dL})$ & $13.21 \pm 1.99$ & $11.25 \pm 0.89$ & $<0.001 * *$ \\
\hline RBCs $\left(10^{6} / \mathrm{uL}\right)$ & $4.63 \pm 0.63$ & $4.69 \pm 0.64$ & $0.653 * *$ \\
\hline Total WBCs (103/uL) & $10.55 \pm 3.29$ & $7.18 \pm 1.29$ & $<0.001 * *$ \\
\hline Platelets (103/uL) & $267.98 \pm 75.36$ & $215.10 \pm 25.37$ & $<0.001^{* *}$ \\
\hline
\end{tabular}

Notes: *P-value of Mann Whitney test. **P-value of Student's $t$-test. P-value $<0.05$ is considered statistically significant, and is bolded.

Abbreviations: ACS, acute coronary syndrome; BP, blood pressure; TC, total cholesterol; LDL-C, low-density lipoproteins cholesterol; HDL-C, high-density lipoproteins cholesterol; Hb, haemoglobin; RBC, red blood cells; WBC, white blood cells. 
Table 3 Serum Levels of Vitamin D2, D3, and the Metabolites Among Participants

\begin{tabular}{|c|c|c|c|}
\hline \multirow[t]{2}{*}{ Parameters } & \multicolumn{2}{|c|}{ Participants $(n=\mid 23)$} & \multirow[t]{2}{*}{ P-value } \\
\hline & ACS Cases* $(n=73)$ Mean $\pm S D$ & Controls $(n=50)$ Mean \pm SD & \\
\hline Vitamin $D_{2}(\mathrm{ng} / \mathrm{mL})$ & $23.48 \pm 5.12$ & $31.64 \pm 6.26$ & $<0.001 *$ \\
\hline Vitamin $D_{3}(\mathrm{ng} / \mathrm{mL})$ & $23.13 \pm 5.64$ & $32.35 \pm 6.31$ & $<0.00 I^{*}$ \\
\hline 25(OH)D (ng/mL) & $14.65 \pm 3.46$ & $24.42 \pm 4.25$ & $<0.001 *$ \\
\hline $\mathrm{I}, 25(\mathrm{OH})_{2} \mathrm{D}(\mathrm{pg} / \mathrm{mL})$ & $45.56 \pm 8.85$ & $65.15 \pm 7.15$ & $<0.001 *$ \\
\hline
\end{tabular}

Notes: Student's t-test was used. *P-value $<0.05$ is considered statistically significant, and is bolded.

Abbreviations: ACS, acute coronary syndrome; $25(\mathrm{OH}) \mathrm{D}, 25$-hydroxyvitamin $\mathrm{D}$; 1,25(OH) 2 , I,25-dihydroxyvitamin D.

studies were conducted on the association between $25(\mathrm{OH})$ $\mathrm{D}$ and myocardial infarction. The current study was a singlecentre study conducted in Saudi Arabia, compared serum vitamin $\mathrm{D}_{2}, \mathrm{D}_{3}$, their metabolites in ACS patients, and age and gender-matched controls without CVD.

Our main finding was a highly significant difference between the ACS cases and the controls regarding all forms of vitamin $\mathrm{D}$ and the two metabolites. The mean vitamin $\mathrm{D}_{2}, \mathrm{D}_{3}, 25(\mathrm{OH}) \mathrm{D}$, and $1,25(\mathrm{OH})_{2} \mathrm{D}$ were significantly lower in the ACS cases compared to the controls (Table 3). Moreover, the $25(\mathrm{OH}) \mathrm{D}$ deficiency was significantly prevalent in our cohort, and there was a significantly higher prevalence in ACS patients (91.4\%) compared to the control group (14\%).

The regression analysis demonstrated the strongly associated predictors with ACS. Low serum levels of 25 $(\mathrm{OH}) \mathrm{D}$ and $1,25(\mathrm{OH})_{2} \mathrm{D}$ significantly predicted ACS occurrence. Moreover, high total cholesterol (TC) and HDL-C significantly predicted ACS, as did high systolic BP. Conversely, the $\mathrm{D}_{2}$ and $\mathrm{D}_{3}$ did not significantly predict the occurrence of ACS.
In line with our findings, several studies have shown the association between deficiency of 25-hydroxyvitamin $\mathrm{D}$ and the risk of CAD or AMI in multiple ethnicities. ${ }^{37-40}$ Moreover, 25(OH)D deficiency has been associated with more severe CAD on coronary angiography. ${ }^{41}$ While subjects with normal serum levels of $25(\mathrm{OH}) \mathrm{D}$ were at a lower risk for AMI compared to $25(\mathrm{OH}) \mathrm{D}$ deficient ones after adjustment for potential confounders. ${ }^{42}$

Additionally, several studies showed that low 25(OH)D prevalence was as high as $68-96 \%$ in ACS patients. ${ }^{43-46}$ Of note, the median serum $25(\mathrm{OH}) \mathrm{D}$ was as low as $18 \mathrm{ng} /$ $\mathrm{mL}$ in 206 AMI patients. $^{47}$

On the other side, the abnormally high $25(\mathrm{OH}) \mathrm{D}$ can be associated with high major adverse cardiac events and total mortality, that is, a U-shape curve. ${ }^{48}$ Rajasree et al enrolled 143 men with CAD and 70 male controls. High levels of $25(\mathrm{OH}) \mathrm{D}(>89 \mathrm{ng} / \mathrm{mL})$ were found in $59.4 \%$ of the CAD cases vs $40.6 \%$ in the controls. CAD patients with high serum $25(\mathrm{OH}) \mathrm{D}$ levels had more than a threefold increase likelihood of having CAD, even after adjusting with multivariate logistic regression. ${ }^{49}$

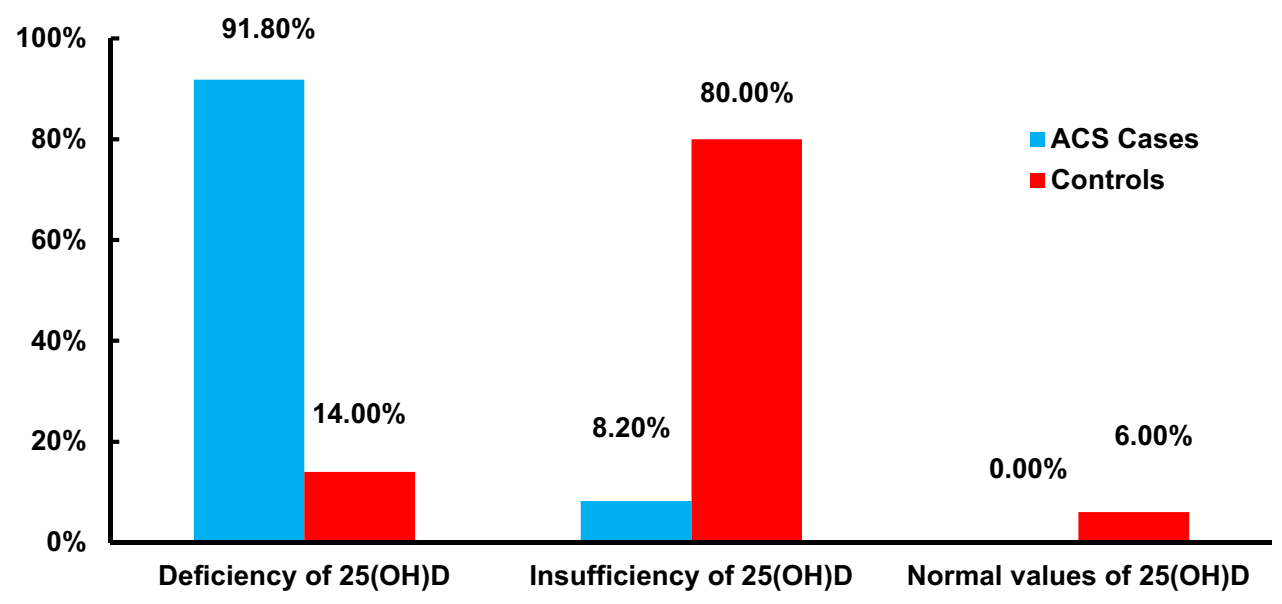

Figure I Distribution of serum $25(\mathrm{OH}) \mathrm{D}$ among the study participants. $25(\mathrm{OH}) \mathrm{D}$ deficiency: serum level $\leq 20 \mathrm{ng} / \mathrm{mL}$, insufficiency: $20.0 \mathrm{I}-29.99 \mathrm{ng} / \mathrm{mL}$, and normal values: $>30 \mathrm{ng} / \mathrm{mL}$.

Abbreviations: ACS, acute coronary syndrome; $25(\mathrm{OH}) \mathrm{D}, 25$-hydroxyvitamin D. 
Table 4 Factors Associated with ACS Among the Study Participants

\begin{tabular}{|l|c|c|c|}
\hline Variables & P-value & Adjusted (OR)** & 95\% CI \\
\hline 25(OH)D (ng/mL) & $\mathbf{0 . 0 1 4 *}$ & 0.218 & $0.065-0.732$ \\
I,25(OH)2D (pg/mL) & $\mathbf{0 . 0 3 4 *}$ & 0.545 & $0.311-0.956$ \\
Systolic BP & $\mathbf{0 . 0 3 8 *}$ & 1.128 & $1.007-1.264$ \\
TC & $\mathbf{0 . 0 4 3 *}$ & 8.286 & $1.073-63.972$ \\
HDL-C & $\mathbf{0 . 0 1 1 ^ { * }}$ & 0.001 & $<0.001-0.040$ \\
\hline
\end{tabular}

Notes: *P-value $<0.05$ is considered statistically significant, and is bolded. **Odds ratio has been adjusted by regression analysis for all possible confounders. Abbreviations: ACS, acute coronary syndrome; $25(\mathrm{OH}) \mathrm{D}, 25$-hydroxyvitamin D; I,25( $\mathrm{OH})_{2} \mathrm{D}$, I,25-dihydroxyvitamin D; BP, blood pressure; TC, total cholesterol; HDLC, high-density lipoproteins cholesterol.

Regarding $1,25(\mathrm{OH})_{2} \mathrm{D}$ or calcitriol status, we found that the active vitamin D metabolite calcitriol is directly correlated to calcidiol. This finding agreed with the work of Dobing et $\mathrm{al}^{50}$ as they showed a significant association between low calcidiol and calcitriol and cardiovascular and total mortality. Renal function is the main factor affecting the serum level of calcitriol. ${ }^{51}$ Renal impairment causes a defective renal hydroxylation of calcidiol; therefore, it was recommended to supplement calcitriol or one of its analogues to those patients to raise their blood level, resulting in increased survival. ${ }^{52}$ Notably, the active form of vitamin D has both cardioprotective and pleiotropic effects and increases thrombomodulin and decreases tissue factor. ${ }^{53}$

In line with our results on the systolic BP as a predictor of ACS, "The Third National Health and Nutrition Examination Survey" has reported a significant increase in the prevalence of hypertension [OR $=1.30, \mathrm{p}<0.001$ ] in patients with low $25(\mathrm{OH}) \mathrm{D}(<21 \mathrm{ng} / \mathrm{mL})$ compared to those patients with level more than $37 \mathrm{ng} / \mathrm{mL} .{ }^{54}$ In addition, a study confirmed the relationship between the TC, low-density lipoprotein cholesterol (LDL-C), HDL-C, and non-HDL-C and ACS vs control group. ${ }^{55}$

Concerning LVEF by echocardiography, we did not find a statistical correlation between the LVEF and vitamin $D_{2}$,

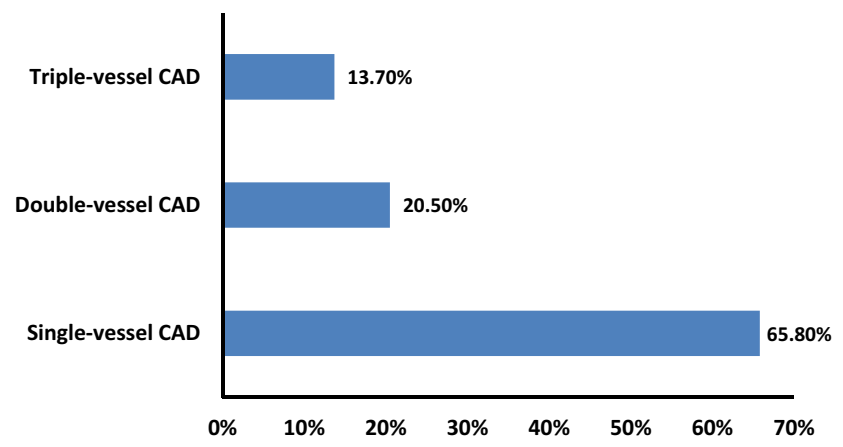

Figure 2 Percentage of single, double and triple vessel CAD among the studied cases of ACS $(n=73)$.

Abbreviations: ACS, acute coronary syndrome; CAD, coronary artery disease.
$\mathrm{D}_{3}$, and metabolites [calcidiol and calcitriol]. In agreement with our finding, Pandit et $\mathrm{al}^{56}$ found no significant association between LVEF and 25(OH)D despite adjustment by age and hypertension treatment. Conversely, Pilz et a ${ }^{57}$ have shown that vitamin D decreased with impaired LV function. Moreover, vitamin D deficiency was significantly associated with sudden cardiac death and death due to heart failure. This study was done on 3,299 patients who were referred for coronary angiography. They did not recruit ACS patients. Our study was on ACS patients and recruited a relatively small number of cases. Interestingly, the early LVEF few days after AMI did not predict the subsequent value. As demonstrated with the study of Chew et al in 2018, they studied 3 cohorts with AMI and found that LVEF showed a $25 \%$ to $37.5 \%$ increase from the baseline $\mathrm{EF}$ during the presentation of AMI to 2-8 weeks post-AMI. ${ }^{58}$

We did not find a statistically significant difference in the vitamin D level between one-vessel and three-vessel disease regarding the coronary angiography results. On the contrary, Syal et al found a significantly higher incidence of double- and triple-vessel CAD in patients with low 25 $(\mathrm{OH}) \mathrm{D}$ compared to those with a normal $25(\mathrm{OH}) \mathrm{D}$ level (53\% and $38 \%$, respectively). ${ }^{41}$ Of note, we do not have any ACS patients with an optimal range of $25(\mathrm{OH}) \mathrm{D}$. Thus, all our patients were in the deficient and insufficient categories of $25(\mathrm{OH}) \mathrm{D}$.

Though the deficiency of vitamin D was significantly associated with CAD and ACS in many studies, the role of vitamin $\mathrm{D}$ supplementation was investigated recently. In the large randomized trial for primary prevention, the Vitamin D and Omega-3 Trial (VITAL), a relatively large supplemental vitamin D (2000 IU) dose failed to reduce the composite endpoint of major cardiovascular events. ${ }^{59}$

\section{Conclusions}

This study showed that vitamin D and all its metabolites were statistically significantly deficient in all patients with 
Table 5 Correlations of Vitamin $D_{2}, D_{3}$, and the Metabolites with the Number of Affected Coronary Arteries and LV Ejection Fraction Among ACS Cases $(n=73)$

\begin{tabular}{|l|c|c|c|c|}
\hline \multirow{2}{*}{ Parameters } & Number of Affected Coronary Arteries (I-3) & \multicolumn{2}{|c|}{ LVEF (\%) } \\
\cline { 2 - 5 } & $\mathbf{r}$ & p-value* & r & p-value* \\
\hline Vitamin D2 (ng/mL) & 0.075 & 0.529 & 0.087 & 0.467 \\
Vitamin D3 (ng/mL) & 0.035 & 0.771 & 0.161 & 0.327 \\
$\mathbf{2 5}(\mathbf{O H}) \mathbf{D}(\mathbf{n g} / \mathbf{m L})$ & 0.044 & 0.710 & 0.155 & 0.190 \\
I,25(OH) $\mathbf{D}(\mathbf{p g} / \mathbf{m L})$ & 0.023 & 0.846 & 0.113 & 0.339 \\
\hline
\end{tabular}

Notes: Spearman correlation was used. *P-value $<0.05$ is considered statistically significant.

Abbreviations: ACS, acute coronary syndrome; r, Spearman correlation coefficient; LVEF, left ventricular ejection fraction; $25(\mathrm{OH}) \mathrm{D}, 25$-hydroxyvitamin $\mathrm{D}$; I,25(OH) $2 \mathrm{D}$, I,25-dihydroxyvitamin D.

ACS compared with the controls. In addition, we demonstrated that $25(\mathrm{OH}) \mathrm{D}, 1,25(\mathrm{OH})_{2} \mathrm{D}$, high systolic $\mathrm{BP}$, total cholesterol, and low HDL-C were statistically significant ACS predictors. Conversely, there was no association between the number of affected coronary vessels and vitamin $\mathrm{D}$ and its metabolites.

\section{Future Research Perspectives}

The clinical benefits of screening and treating vitamin D deficiency might reduce CVD morbidity and mortality. Thus, vitamin D supplementation is recognized as a potential therapeutic agent in patients with vitamin
D insufficiency/deficiency and cardiovascular diseases. However, vitamin D administration has many challenges, including possible high toxicity levels and low bioavailability. Thus, a potential new method such as using nanotechnologies to deliver the optimal amount of vitamin D either by incorporating into foods or therapies to enhance vitamin D bioavailability and effectiveness and overcome some of the drawbacks of the traditional way of administration. ${ }^{60}$ We suggest that acute administration of $25(\mathrm{OH}) \mathrm{D}$, or $1,25(\mathrm{OH})_{2} \mathrm{D}$ for admitted ACS patients in large interventional randomized clinically controlled trials might improve patients' outcomes. However, further

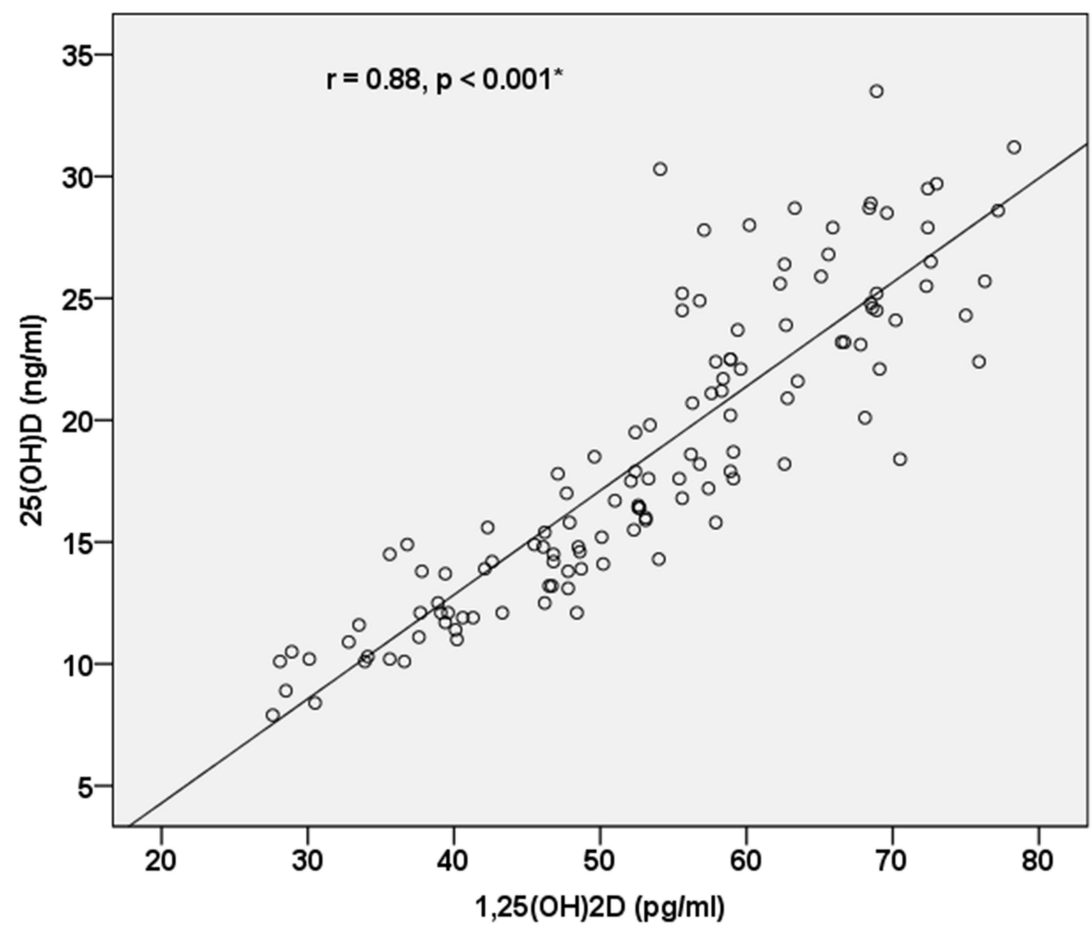

Figure 3 Correlation between $25(\mathrm{OH}) \mathrm{D}$ and $\mathrm{I}, 25(\mathrm{OH})_{2} \mathrm{D}$ levels among the studied acute coronary syndrome cases $(\mathrm{n}=73)$.

Notes: Pearson's correlation was used. *P-value $<0.05$ is considered statistically significant, and bolded.

Abbreviations: ACS, acute coronary syndrome; r, Pearson's correlation coefficient; $25(\mathrm{OH}) \mathrm{D}$, 5-hydroxyvitamin $\mathrm{D} ; \mathrm{I}, 25(\mathrm{OH}){ }_{2} \mathrm{D}, \mathrm{I}, 25-\mathrm{dihydroxyvitamin} \mathrm{D}$. 
factors should be considered with supplementation of vitamin D. Those include but are not limited to parathormone, phosphate, renin, and fibroblast growth factor.

Dual actions of VDR in transcription and non-genomic activation of RhoA-Rho-associated coiled kinase (ROCK), p38 mitogen-activated protein kinase (p38MAPK), and mitogen- and stress-activated kinase 1 (MSK1) may be a useful molecular therapeutic target to develop novel cardioprotective drugs. ${ }^{61}$ It was reported that vitamin D mitigated cardiomyocyte apoptosis, mitochondrial fission, mitophagy, and their ultrastructural abnormalities. Targeting signalling networks of inflammation and oxidative stress may be helpful. However, multitargeting cardioprotective therapeutic strategies should be adopted to tackle both inflammatory and noninflammatory cardiac injury pathways consequent to ACS. Bio-intervention in complex structure one is suggested as a new therapeutic target. Mitophagy has dual beneficial and harmful effects for mitochondrial control, quality and cell survival. There are several creative multicenter approaches to hasten translational research for developing novel molecular therapy for cardioprotection and prevention of ACS. These include targeting mitochondrial damage, oxidative stress, and calcium overload, obstructed coronary microcirculation, activation of platelets and other critical pathways. Another innovative targeting includes engineered exosomal peptides that enhanced cardiomyocyte uptake, reduced apoptosis and high cardiac protection. Experimental intramyocardial microinjection opens a new arena for future gene therapy and improves the functional capacity of the heart. So, advances in nano-cardio medicine have huge potential future promising novel therapeutic agents for diagnosing, treating, and preventing acute coronary syndromes.

\section{Strength and Limitations}

Several studies were carried out on the association between the $25(\mathrm{OH}) \mathrm{D}$ levels and the $\mathrm{ACS},{ }^{37,39}$ yet, there is no single study, up to the best of our knowledge, on the association of different forms and metabolites of vitamin $\mathrm{D}$ and the occurrence of ACS on our population. Therefore, the strength of the current research is the study of the potential association between different forms and metabolites of vitamin D and ACS in our population. Our study has some limitations that need to be acknowledged. The sample of patients was only conducted from a single centre at a single time point. A small study sample reduces the power of event-free survival analysis, and the results obtained thus cannot be generalized globally to all ACS patients. These data can only be used to generate hypotheses that can be used in the future for a confirmatory study, ie, a mega randomized clinical trial. Since this, an observational study, many different techniques that can be applied to prevent or control for confounding could not be used. The most commonly confounding factors that are hard to measure and adjust are limited physical activity, sun exposure, and diet. Moreover, the study did not consider the socioeconomic variables between the two groups that significantly influence vitamin $\mathrm{D}$ deficiency risk.

\section{Abbreviations}

ACS, acute coronary syndrome; AMI, acute myocardial infarction; BP, blood pressure; BMI, body mass index; $\mathrm{CAD}$, coronary artery disease; CVD, cardiovascular disease; DM, diabetes mellitus; D2, vitamin D2; D3, vitamin D3; ECG, electrocardiogram; HbA1c, glycated haemoglobin; HDL-C, high-density lipoprotein cholesterol; LDL-C, low-density lipoprotein cholesterol; LVEF, left ventricular ejection fraction; NF- $\kappa \mathrm{B}$, nuclear factor- $\kappa \mathrm{B}$; TC, total cholesterol; VDRs, vitamin $\mathrm{D}$ receptors; VITAL, vitamin $\mathrm{D}$ and Omega-3 trial; 25(OH)D, 25-hydroxyvitamin D; 1,25(OH $)_{2} \mathrm{D}$, 1,25-dihydroxyvitamin D; ROCK, RhoARho-associated coiled kinase; p38MAPK, p38 mitogenactivated protein kinase; MSK1, mitogen- and stressactivated kinase 1 .

\section{Disclosure}

The authors report no conflicts of interest related to this work.

\section{References}

1. GBD 2013 Mortality and Causes of Death Collaborators. Global, regional, and national age-sex specific all-cause and cause-specific mortality for 240 causes of death, 1990-2013: a systematic analysis for the Global Burden of Disease Study 2013. Lancet. 2015;385 (9963):117-171. doi:10.1016/S0140-6736(14)61682-2.

2. Wang H, Chen W, Li D, et al. Vitamin D and chronic diseases. Aging Dis. 2017;8(3):346-353. doi:10.14336/AD.2016.1021

3. Hossein-nezhad A, Holick MF. Vitamin D for health: a global perspective. Mayo Clin Proc. 2013;88(7):720-755. doi:10.1016/j. mayocp.2013.05.011

4. Ganji V, Zhang X, Tangpricha V. Serum 25-hydroxyvitamin $\mathrm{D}$ concentrations and prevalence estimates of hypovitaminosis D in the U.S. population based on assay-adjusted data. J Nutr. 2012;142 (3):498-507. doi:10.3945/jn.111.151977

5. Greene-Finestone LS, Berger C, de Groh M, et al. 25-hydroxyvitamin $\mathrm{D}$ in Canadian adults: biological, environmental, and behavioral correlates. Osteoporos Int. 2011;22(5):1389-1399. doi:10.1007/ s00198-010-1362-7

6. Cashman KD, Dowling KG, Škrabáková Z, et al. Vitamin D deficiency in Europe: pandemic? Am J Clin Nutr. 2016;103(4):1033-1044. doi:10.3945/ajen.115.120873 
7. Tuffaha M, El Bcheraoui C, Daoud F, et al. Deficiencies under plenty of sun: vitamin D status among adults in the Kingdom of Saudi Arabia, 2013. N Am J Med Sci. 2015;7(10):467-475. doi:10.4103/ 1947-2714.168675

8. Al-Daghri NM, Al-Saleh Y, Aljohani N, et al. Vitamin D deficiency and cardiometabolic risks: a juxtaposition of Arab adolescents and Adults. PLoS One. 2015;10(7):e0131315. doi:10.1371/journal. pone. 0131315

9. Holick MF. The vitamin D deficiency pandemic: approaches for diagnosis, treatment and prevention. Rev Endocr Metab Disord. 2017;18(2):153-165. doi:10.1007/s11154-017-9424-1

10. Bijaya M, Kumar KS, Satish P. Association of vitamin D deficiency and acute coronary syndrome, our experience. Integr $J$ Glob Health. 2018;2(1):1-5

11. Milazzo V, De Metrio M, Cosentino N, Marenzi G, Tremoli E. Vitamin D and acute myocardial infarction. World $J$ Cardiol. 2017;9(1):14-20. doi:10.4330/wjc.v9.i1.14

12. Sung KC, Chang Y, Ryu S, Chung HK. High levels of serum vitamin $\mathrm{D}$ are associated with a decreased risk of metabolic diseases in both men and women, but an increased risk for coronary artery calcification in Korean men. Cardiovasc Diabetol. 2016;15(1):112. doi:10.1186/s12933-016-0432-3

13. Gonzalez-Parra E, Rojas-Rivera J, Tuñón J, Praga M, Ortiz A, Egido J. Vitamin D receptor activation and cardiovascular disease. Nephrol Dial Transplant. 2012;27(Suppl 4):iv17-iv21. doi:10.1093/ ndt/gfs534

14. Lee TL, Lee MH, Chen YC, et al. Vitamin D attenuates ischemia/ reperfusion-induced cardiac injury by reducing mitochondrial fission and mitophagy. Front Pharmacol. 2020;11:604700. doi:10.3389/ fphar.2020.604700

15. Verdoia M, Pergolini P, Rolla R, et al. Impact of high-dose statins on vitamin $\mathrm{D}$ levels and platelet function in patients with coronary artery disease. Thromb Res. 2017;150:90-95. doi:10.1016/j. thromres.2016.12.019

16. Christodoulidis G, Vittorio TJ, Fudim M, Lerakis S, Kosmas CE. Inflammation in coronary artery disease. Cardiol Rev. 2014;22 (6):279-288. doi:10.1097/CRD.0000000000000006

17. Santoro D, Caccamo D, Lucisano S, et al. Interplay of vitamin D, erythropoiesis, and the renin-angiotensin system. Biomed Res Int. 2015;2015:145828. doi:10.1155/2015/145828

18. Lee JH, O'Keefe JH, Bell D, Hensrud DD, Holick MF. Vitamin $\mathrm{D}$ deficiency an important, common, and easily treatable cardiovascular risk factor? J Am Coll Cardiol. 2008;52(24):1949-1956. doi:10.1016/j.jacc.2008.08.050

19. Chen S, Swier VJ, Boosani CS, Radwan MM, Agrawal DK. Vitamin $\mathrm{D}$ deficiency accelerates coronary artery disease progression in swine. Arterioscler Thromb Vasc Biol. 2016;36(8):1651-1659. doi:10.1161/ATVBAHA.116.307586

20. Khalili H, Talasaz AH, Salarifar M. Serum vitamin D concentration status and its correlation with early biomarkers of remodeling following acute myocardial infarction. Clin Res Cardiol. 2012;101 (5):321-327. doi:10.1007/s00392-011-0394-0

21. Borji S, Rafieian-Kopaei M. Vitamin D and its importance on public health. J Parathyr Dis. 2016;4(1):20-24.

22. Armas LA, Hollis BW, Heaney RP. Vitamin D2 is much less effective than vitamin D3 in humans. J Clin Endocrinol Metab. 2004;89 (11):5387-5391. doi:10.1210/jc.2004-0360

23. Chun RF, Hernandez I, Pereira R, et al. Differential responses to vitamin D2 and vitamin D3 are associated with variations in free 25-hydroxyvitamin D. Endocrinology. 2016;157(9):3420-3430. doi:10.1210/en.2016-1139

24. Christakos S, Ajibade DV, Dhawan P, Fechner AJ, Mady LJ. Vitamin D: metabolism. Endocrinol Metab Clin North Am. 2010;39 (2):243-253. doi:10.1016/j.ecl.2010.02.002
25. Whelton PK, Carey RM, Aronow WS, et al. 2017 ACC/AHA/AAPA/ $\mathrm{ABC} / \mathrm{ACPM} / \mathrm{AGS} / \mathrm{APhA} / \mathrm{ASH} / \mathrm{ASPC}$ NMA/PCNA guideline for the prevention, detection, evaluation, and management of high blood pressure in adults: a report of the American College of Cardiology/ American Heart Association Task Force on Clinical Practice Guidelines. J Am Coll Cardiol. 2018;71(19):e127-e248. doi:10.1016/j.jacc.2017.11.006

26. American Diabetes Association. 2. classification and diagnosis of diabetes: standards of medical care in diabetes-2020. Diabetes Care. 2020;43(Suppl 1):S14-S31. doi:10.2337/dc20-S002.

27. Birmpili E, Katsiki N, Malhotra A, Dimopoulou E, Mikhailidis DP, Tsiligiroglou-Fachantidou A. Gender and socio-economic differences in daily smoking and smoking cessation among adult residents in a Greek rural area. Open Cardiovasc Med J. 2012;6:15-21. doi:10.2174/1874192401206010015

28. Grundy SM, Stone NJ; Guideline Writing Committee for the 2018 Cholesterol Guidelines. 2018 cholesterol clinical practice guidelines: synopsis of the 2018 American Heart Association/American College of Cardiology/Multisociety Cholesterol Guideline. Ann Intern Med. 2019;170(11):779-783. doi:10.7326/M19-0365

29. Mach F, Baigent C, Catapano AL, et al. 2019 ESC/EAS guidelines for the management of dyslipidaemias: lipid modification to reduce cardiovascular risk. Eur Heart J. 2020;41(1):111-188. doi:10.1093/ eurheartj/ehz455

30. Holmes MV, Asselbergs FW, Palmer TM, et al. Mendelian randomization of blood lipids for coronary heart disease. Eur Heart J. 2015;36(9):539-550. doi:10.1093/eurheartj/eht571

31. Braunwald E, Antman EM, Beasley JW, et al. ACC/AHA guidelines for the management of patients with unstable angina and non-STsegment elevation myocardial infarction. A report of the American College of Cardiology/American Heart Association Task Force on Practice Guidelines (Committee on the Management of Patients With Unstable Angina). J Am Coll Cardiol. 2000;36(3):970-1062. doi:10.1016/s0735-1097(00)00889-5

32. Roy A, Lakshmy R, Tarik M, Tandon N, Reddy KS, Prabhakaran D. Independent association of severe vitamin D deficiency as a risk of acute myocardial infarction in Indians. Indian Heart $J$. 2015;67 (1):27-32. doi:10.1016/j.ihj.2015.02.002

33. Anderson JL, Adams CD, Antman EM, et al. 2011 ACCF/AHA focused update incorporated into the ACC/AHA 2007 guidelines for the management of patients with unstable angina/non-ST-elevation myocardial infarction: a report of the American College of Cardiology Foundation/American Heart Association Task Force on Practice Guidelines. Circulation. 2011;123(18):e426-e579. doi:10.1161/CIR.0b013e318212bb8b

34. Wang Z, Senn T, Kalhorn T, et al. Simultaneous measurement of plasma vitamin $\mathrm{D}(3)$ metabolites, including 4 3,25 -dihydroxyvitamin D(3), using liquid chromatography-tandem mass spectrometry. Anal Biochem. 2011;418(1):126-133. doi:10.1016/j.ab.2011.06.043

35. Holick MF, Binkley NC, Bischoff-Ferrari HA, et al. Evaluation, treatment, and prevention of vitamin D deficiency: an Endocrine Society clinical practice guideline. J Clin Endocrinol Metab. 2011;96(7):1911-1930. doi:10.1210/jc.2011-0385

36. Palacios C, Gonzalez L. Is vitamin D deficiency a major global public health problem? J Steroid Biochem Mol Biol. 2014;144(Pt A):138-145. doi:10.1016/j.jsbmb.2013.11.003

37. Giovannucci E, Liu Y, Hollis BW, Rimm EB. 25-hydroxyvitamin D and risk of myocardial infarction in men: a prospective study. Arch Intern Med. 2008;168(11):1174-1180. doi:10.1001/archinte.168.11.1174

38. Mohammad AM, Shammo NA, Jasem JA. Vitamin D status in acute myocardial infarction: a case-control study. Cardiovasc Endocrinol Metab. 2018;7(4):93-96. doi:10.1097/XCE.0000000000000160

39. de Boer IH, Kestenbaum B, Shoben AB, Michos ED, Sarnak MJ, Siscovick DS. 25-hydroxyvitamin D levels inversely associate with risk for developing coronary artery calcification. J Am Soc Nephrol. 2009;20(8):1805-1812. doi:10.1681/ASN.2008111157 
40. Messenger W, Nielson CM, Li H, et al. Serum and dietary vitamin $\mathrm{D}$ and cardiovascular disease risk in elderly men: a prospective cohort study. Nutr Metab Cardiovasc Dis. 2012;22(10):856-863. doi:10.1016/j.numecd.2010.10.019

41. Syal SK, Kapoor A, Bhatia E, et al. Vitamin D deficiency, coronary artery disease, and endothelial dysfunction: observations from a coronary angiographic study in Indian patients. $J$ Invasive Cardiol. 2012;24(8):385-389.

42. Iqbal MP, Mehboobali N, Azam I, Tareen AK. Association of alkaline phosphatase with acute myocardial infarction in a population with high prevalence of hypovitaminosis D. Clin Chim Acta. 2013;425:192-195. doi:10.1016/j.cca.2013.08.009

43. Lee JH, Gadi R, Spertus JA, Tang F, O’Keefe JH. Prevalence of vitamin $\mathrm{D}$ deficiency in patients with acute myocardial infarction. Am J Cardiol. 2011;107(11):1636-1638. doi:10.1016/j.amjcard.2011.01.048

44. Ng LL, Sandhu JK, Squire IB, Davies JE, Jones DJ. Vitamin D and prognosis in acute myocardial infarction. Int $J$ Cardiol. 2013;168 (3):2341-2346. doi:10.1016/j.ijcard.2013.01.030

45. Aleksova A, Belfiore R, Carriere C, et al. Vitamin D deficiency in patients with acute myocardial infarction: an Italian single-center study. Int J Vitam Nutr Res. 2015;85(1-2):23-30. doi:10.1024/03009831/a000220

46. De Metrio M, Milazzo V, Rubino M, et al. Vitamin D plasma levels and in-hospital and 1-year outcomes in acute coronary syndromes: a prospective study. Medicine (Baltimore). 2015;94(19):e857. doi:10.1097/MD.0000000000000857

47. Correia LC, Sodré F, Garcia G, et al. Relation of severe deficiency of vitamin $\mathrm{D}$ to cardiovascular mortality during acute coronary syndromes. Am J Cardiol. 2013;111(3):324-327. doi:10.1016/j. amjcard.2012.10.006

48. Jia X, Aucott LS, McNeill G. Nutritional status and subsequent all-cause mortality in men and women aged 75 years or over living in the community. Br J Nutr. 2007;98(3):593-599. doi:10.1017/ S0007114507725163

49. Rajasree S, Rajpal K, Kartha CC, et al. Serum 25-hydroxyvitamin D3 levels are elevated in South Indian patients with ischemic heart disease. Eur J Epidemiol. 2001;17(6):567-571. doi:10.1023/ a:1014559600042

50. Dobnig H, Pilz S, Scharnagl H, et al. Independent association of low serum 25-hydroxyvitamin $\mathrm{d}$ and 1,25-dihydroxyvitamin d levels with all-cause and cardiovascular mortality. Arch Intern Med. 2008;168 (12):1340-1349. doi:10.1001/archinte.168.12.1340
51. Holick MF. Vitamin D deficiency. $N$ Engl J Med. 2007;357 (3):266-281. doi:10.1056/NEJMra070553

52. Kovesdy CP, Ahmadzadeh S, Anderson JE, Kalantar-Zadeh K. Association of activated vitamin D treatment and mortality in chronic kidney disease. Arch Intern Med. 2008;168(4):397-403. doi:10.1001/ archinternmed.2007.110

53. Saheb Sharif-Askari F, Saheb Sharif-Askari N, Halwani R, Abusnana S, Hamoudi R, Sulaiman N. Low vitamin D serum level is associated with HDL-C dyslipidemia and increased serum thrombomodulin levels of insulin-resistant individuals. Diabetes Metab Syndr Obes. 2020;13:1599-1607. doi:10.2147/DMSO.S245742

54. Martins D, Wolf M, Pan D, et al. Prevalence of cardiovascular risk factors and the serum levels of 25-hydroxyvitamin D in the United States: data from the Third National Health and Nutrition Examination Survey. Arch Intern Med. 2007;167(11):1159-1165. doi:10.1001/archinte.167.11.1159

55. Bahulikar A, Tickoo V, Phalgune D. Association of non-HDL cholesterol, homocysteine and vitamin $\mathrm{D}$ in acute coronary syndrome. $J$ Assoc Physicians India. 2018;66(8):22-25.

56. Pandit A, Mookadam F, Boddu S, et al. Vitamin D levels and left ventricular diastolic function. Open Heart. 2014;1(1):e000011. doi:10.1136/openhrt-2013-000011

57. Pilz S, März W, Wellnitz B, et al. Association of vitamin D deficiency with heart failure and sudden cardiac death in a large cross-sectional study of patients referred for coronary angiography. J Clin Endocrinol Metab. 2008;93(10):3927-3935. doi:10.1210/jc.2008-0784

58. Chew DS, Heikki H, Schmidt G, et al. Change in left ventricular ejection fraction following first myocardial infarction and outcome. JACC Clin Electrophysiol. 2018;4(5):672-682. doi:10.1016/j. jacep.2017.12.015

59. Manson JE, Cook NR, Lee IM, et al. Vitamin D supplements and prevention of cancer and cardiovascular disease. $N$ Engl J Med. 2019;380(1):33-44. doi:10.1056/NEJMoa1809944

60. Ramalho MJ, Coelho MA, Pereira MC. Nanoparticles for delivery of vitamin D: challenges and opportunities. In: Gowder S, editor. A Critical Evaluation of Vitamin D-Clinical Overview. Dimensions; 2017:11.

61. Ordóñez-Morán P, Larriba MJ, Pálmer HG, et al. RhoA-ROCK and p38MAPK-MSK1 mediate vitamin D effects on gene expression, phenotype, and Wnt pathway in colon cancer cells. J Cell Biol. 2008;183(4):697-710. doi:10.1083/jcb.200803020
Vascular Health and Risk Management

\section{Publish your work in this journal}

Vascular Health and Risk Management is an international, peerreviewed journal of therapeutics and risk management, focusing on concise rapid reporting of clinical studies on the processes involved in the maintenance of vascular health; the monitoring, prevention and treatment of vascular disease and its sequelae; and the involvement of metabolic disorders, particularly diabetes. This journal is indexed on PubMed Central and MedLine. The manuscript management system is completely online and includes a very quick and fair peerreview system, which is all easy to use. Visit http://www.dovepress. com/testimonials.php to read real quotes from published authors. 